\title{
Consent in Alzheimer's Disease Research: Risk/Benefit Factors
}

\author{
B. Lynn Beattie
}

\begin{abstract}
In the era of chronic disease, we are challenged to find therapies that provide symptomatic relief and ideally, alter the course of the underlying disease. In Alzheimer's disease (AD), these issues are complicated by the disease itself, which affects the subject's decision-making capacity for participation in the research. According to established ethical guidelines it is clear that individuals with impaired capacity may participate in research and their risk should be no greater than that which the individual would have in day to day activities with anticipation of benefits within that realm. Decision making processes are complex and involve proxies who themselves have biases about their loved one and the potential for participating in the research. Newer disease-modifying approaches such as immunotherapy have potential for affecting the course of the underlying disease but with greater risk of more significant side effects. Ideally the health care of the subjects is not disadvantaged by research participation. At the same time, trials of potentially riskier therapy are relevant in subjects with the disease. Research for subjects with AD must have appropriate safeguards in place to enable effective progress in innovative therapy for a vulnerable, often elderly population. Recommendations are made which could further our capacity to undertake ethical research in the AD population.
\end{abstract}

RÉSUMÉ: Le consentement à la recherche sur la maladie d'Alzheimer : facteurs de risques/bénéfices : À l'ère des maladies chroniques, trouver des traitements qui apportent un soulagement symptomatique et qui, idéalement, altèrent l'évolution naturelle de la maladie est un défi. Dans la maladie d'Alzheimer (MA), la maladie elle-même complique la situation compte tenu du fait que la maladie affecte la capacité du sujet à décider de sa participation à la recherche. Selon les lignes directrices éthiques établies, il est clair que les individus dont la capacité à décider est altérée peuvent participer à la recherche et les risques encourus ne devraient pas être plus grands que ceux auxquels il est exposé dans ses activités quotidiennes et les bénéfices anticipés devraient être dans ce domaine. Les processus de décision sont complexes et impliquent des mandataires qui sont eux-mêmes biaisés à propos de leurs proches et de leur participation à la recherche. Les approches nouvelles, qui modifient l'évolution de la maladie comme l'immunothérapie, offrent la possibilité de modifier l'évolution de la maladie sous-jacente mais au prix d'un risque d'effets secondaires plus importants. Idéalement, les sujets ne doivent pas être désavantagés quant à leurs soins de santé à cause de leur participation à la recherche. Néanmoins, les essais de traitements potentiellement plus risqués sont pertinents pour les sujets atteints de la maladie. La recherche chez les sujets atteints de la MA doit comporter des mesures de protection appropriées permettant de développer des traitements novateurs destinés à une population vulnérable, souvent âgée. Nous faisons des recommandations qui pourraient améliorer notre capacité à faire une recherche éthique dans la population atteinte de la MA.

Can. J. Neurol. Sci. 2007; 34: Suppl. 1 - S27-31

The Canadian Tri-Council Policy Statement (TCPS), Ethical Conduct for Research Involving Humans (2005) provides the guiding ethical principles for research protocols in Canada. ${ }^{1}$ Ethical conduct is a dynamic process, particularly as applications with higher risk and a need for more intense ethical debate are surfacing.

This paper addresses some of the factors for ethical conduct, including risk, benefit, consent, and assent, for trials of interventions for Alzheimer's disease (AD), generally, and the application of these principles to the example of emerging immunotherapy for $\mathrm{AD}$, a therapy with more than minimal risk and potential disease modifying benefit.

\section{RISK}

Risk refers to the fact that there is a possibility that harm may occur, expressed as chance (probability) and severity (magnitude) of the envisioned harm. When considering risk, equipoise is a fundamental feature. It encompasses "a clear moral foundation to the requirement that the health care of subjects not be disadvantaged by research participation"(TCPS, 2005, Section 1, 7.A). ${ }^{1}$

When the research provides that "potential subjects can reasonably be expected to regard the probability and magnitude

From the Department of Medicine, Division of Geriatric Medicine, University of British Columbia, Vancouver, BC, Canada.

Received October 31, 2005. ACCEPTED In FinAl Form April 8, 2006.

Reprint requests to: B. Lynn Beattie, Division of Geriatric Medicine, Vancouver Hospital \& Health Sciences Centre, 2211 Wesbrook Mall, Room S124, Vancouver, BC, V6T 2B5, Canada. 
of possible harms implied by participation in the research to be no greater than those encountered by the subject in those aspects of his or her everyday life that relate to the research, then the research can be regarded as within the range of minimal risk. Above the threshold of minimal risk, the research warrants a higher degree of scrutiny and greater provision for the protection of the interests of prospective subjects" (TCPS, 2005, C.C1). ${ }^{1}$ A description of reasonably foreseeable harms is required as part of informed consent.

\section{Risk BENEFIT BaLANCE}

Benefit refers to positive value related to health or welfare. "Risk is properly contrasted to probability of benefits and benefits are properly contrasted with harms rather than risks of harm". ${ }^{2}$ Clinical trials may be conducted with desperate populations with limited or exhausted therapeutic options. This may distort the perceptions of risk benefit balance by subjects and their families, as well as by researchers. The TCPS (2005, C.5.3) underlines the need to minimize harms and ensure that these harms are proportionate to the benefits that might be expected from the knowledge gained - the principle of equipoise. ${ }^{1}$ Beneficence requires that we consider not only the risk of harm to subjects but also the loss of potential benefits gained from the research were it not to be done.

\section{WiTHDRAWAL}

Participation in research must allow the subject the "right to withdraw at any time without prejudice to pre-existing entitlements, and (the subject) will be given continuing and meaningful opportunities for deciding whether or not to continue to participate" [TCPS, 2005, Section 2D, 2.4 (d)]. ${ }^{1}$ When third parties are involved, they should be those who are most likely to understand the incompetent subject's situation and to act in that person's best interest. This person should be given an opportunity to observe the research as it proceeds in order to be able to withdraw the subject from the research, if such action appears in the subject's best interest.

A subject may withdraw from a study and not be able to withdraw from or avoid the (longer-term) consequences of participating in the study. For example, if an intervention has significant side effects, the subject may withdraw from the study, but with continuing consequences of the intervention. The ethical physician must continue to provide an appropriate high level of care.

\section{COMPETENCE AND INFORMED CONSENT}

Informed consent must be voluntarily given, without manipulation, undue influence, or coercion. "Those who are not competent to consent for themselves shall not be automatically excluded from research that is potentially beneficial to them as individuals, or to the group that they represent (TCPS, 2005, Section 5, C.5.3). ${ }^{1}$ Incompetence can be caused by AD and clinical trials for interventions must include those with the disease. Subjects not legally competent can be research subjects when (TCPS, 2005, Section 2, E.2.5): ${ }^{1}$

a) The research question can only be addressed using individuals within the identified group(s); and

b) Free and informed consent will be sought from their authorized representative(s); and c) The research does not expose them to more than minimal risks without the potential for direct benefits for them.

Impaired persons may be competent to make simple treatment decisions but are often incompetent to make complex ones that require weighing and balancing the risks and benefits of alternative treatments and factoring in uncertainty about outcomes. Thresholds for competence to make treatment decisions could comprise a sliding scale. Just as thresholds for competence vary according to the complexity and uncertainty of the decision, the threshold for scrutiny should increase as the risks of the intervention and the uncertainty of its benefits increase.

The process of informed consent requires understanding the information about the study and reasoned judgment about participation. Buckles et $\mathrm{al}^{3}$ studied understanding of informed consent by demented individuals and found that very mild and mild dementia individuals could understand the study. This understanding was re-inforced by two presentations of the consent information. The implication of this work was that as the severity of dementia increased a caregiver should be involved with the consent process. Hirschman et $\mathrm{al}^{4}$ examined prospectively a cohort of AD patient-caregiver Dyads to examine when transition to loss of capacity for medical decision making took place. The threshold was marked by an MMSE (MiniMental State Examination) less than 20 and older persons were more likely to depend on caregivers for decisions.

\section{Proxy Consent}

Proxy consent is a common consideration for research with $\mathrm{AD}$ subjects, who by the nature of the disease have limited capacity which worsens over time. Kim et $\mathrm{al}^{5}$ however, reported that in a survey of Alzheimer's Disease Cooperative Study centers, $14 \%$ or four sites reported that their institutional review boards would not allow any type of proxy consent. In three of the four sites doing clinical trials with MMSE scores ranging from 13 to 26,85 to $100 \%$ of subjects were capable of consenting to the clinical trial, a much higher range of percentages than for the sites that employed surrogate consent procedures.

The proxy is in an unenviable position, at times caught between justifiable persuasion and undue influence. A further complication is that $\mathrm{AD}$ is a disease of older persons and spouses who are often the proxies are vulnerable by virtue of age themselves to have altered competency due to dementia such as AD. Pucci et al, ${ }^{6}$ in an empirical analysis of patients and caregivers, found ADAS-cog (Alzheimer Disease Assessment Scale cognitive) and MMSE were the tests most significantly correlated to competency; MMSE below 18 had a positive predictive value of $95 \%$ and a negative predictive value of $63.3 \%$. Of interest among caregivers, none were incompetent, but $20 \%$ (8 subjects) were marginally competent, 50\% (20 subjects) were sufficiently competent, and 30\% (12 subjects) were completely competent. Whether the caregivers were participating with subjects in randomized clinical trials or not, made no difference. Seventy percent of caregivers without evidence of cognitive and thought disorders were considered unable to describe clearly why and how placebo, randomization, and double-blind procedures are used, or to appreciate clinical equipoise. This is further confirmation that the consent information is difficult to understand, even for non-demented 
persons who have, as well, authority as legal representatives for those with altered competence.

If the caregivers have the primary responsibility for informed consent, will they consent for subjects who have limited decision-making capacity, but a desire to participate? Insight and judgment may not be lost by the subject even in the early stages of the disorder. Informed consent given by a disinterested legal advisor is seen as an alternative, but is more cumbersome than allowing an autonomous subject to choose whether to enroll in research. At the same time, the subject would unlikely be able to participate (i.e., would be excluded from participating in the clinical trial) if the legal alternative were not available. The knowledgeable person (proxy, Substitute Decision Maker, legal alternative) has several roles besides signing the informed consent. These include being the "memory" for the subject who is participating; bringing the person to scheduled appointments and making appropriate arrangements; observing the subject for adverse events, including those which should be reported immediately to the research team, as well as those of less urgent nature; ensuring that the subject takes medications as required; observing and reporting benefits from the treatment trial; relaying to the investigators the subject's objection to enrollment or to continued participation; and taking part in measures of evaluation of efficacy of pharmacologic agents, such as change in emotional burden or time spent on tasks for care.

A number of concerning issues arise from studies on Proxy Consent. Warren et $\mathrm{al},{ }^{7}$ in a study of use of urinary catheters in long-term care, found that nearly a third of those proxies, who believed the patient would have refused to participate, gave permission against the apparent wishes of the subject. In 1989, Ouslander et $\mathrm{al}^{8}$ evaluated two high- and two low-risk vignettes and found a low rate of agreement between what the patient chose and what their proxies thought they would choose. Agreement was best between patients and family member proxies. ${ }^{8}$ Seckler et al, ${ }^{9}$ using a hypothetical medical scenario, looked at surrogate decisions compared with decisions by competent chronically ill elderly. Patients predicted that their physicians and family members would accurately represent their wishes: neither did. ${ }^{9}$ Sachs et al, ${ }^{10}$ studied dementia patients, proxies, and well elderly using four vignettes describing different types of dementia research. Dementia patients' willingness to participate declined as the invasiveness of the procedures increased. ${ }^{10}$ For three of the four vignettes, proxies were most willing to give consent, followed by the well elderly, and then the patients with dementia. Muncie et al, ${ }^{11}$ using ten hypothetical research studies, studied competent seniors and their likely proxies. They found that proxies were not able to effectively guess the decisions of the seniors and proxies made decisions on what they themselves would want in that situation. ${ }^{11}$

Williams et $\mathrm{al}^{12}$ and Lewis et $\mathrm{al}^{13}$ raised further concern about selection bias introduced by the process of informed consent given by proxy. Clinical applicability of the results of a therapeutic trial depends on the degree to which data can be extrapolated from a select group of subjects to the general population, especially where subjects' comprehension of information and competence to give consent may be compromised. ${ }^{12,13}$ Sugarman et $\mathrm{al}^{14}$ evaluated proxy decisionmaking and informed consent processes. Proxies gave the following reasons for participation: hope of direct or indirect benefits to subjects, carers, descendants; desperation; trust in the investigator; belief in the goodness of research; and altruism. ${ }^{14}$ The burden of the decision was influenced by a number of factors, including risk and nature of the study, extent to which subjects were able to participate, duration, and severity of dementia. Karlawish and Casarett ${ }^{15}$ underline that burden and depression may adversely influence decisions. Participation of caregivers with low burden may affect outcome. A single casecontrol study has suggested that participation in a clinical trial reduces the odds of placement in a long-term-care facility. ${ }^{15}$ In addition giving proxy consent may impose an additional burden on an already burdened carer. We cannot assume that ethical standards for research involving incompetent subjects have been assured through consent from legal alternatives. At the same time, as Kim et $\mathrm{al}^{5}$ summarized from one study, when asked about their research participation should they become incapacitated, subjects would endorse their family's overriding a negative advance directive if the research were potentially beneficial for the subject.

The principle of Double Informed Consent is a consideration when a subject has dementia such as AD. ${ }^{16}$ There is evidence that individuals with very mild and mild disease have capacity to understand. However, subjects may be enrolled with more severe disease and many studies such as clinical trials of therapies are longitudinal and capacity may change over time. Double Informed Consent includes the subject and the caregiver. In moderate to severe disease the subject may in fact give assent. This principle is also relevant if the subject's capacity is fluctuating. Consideration for obtaining Double Informed Consent is a reality for studies for AD subjects or those with other dementias since the caregiver plays such an important role as advocate, monitor and logistical supporter.

Individuals who lack capacity to give consent may give assent, which is seen to be a less demanding standard of research authorization. Persistent objection should be generally accepted as grounds for dissent and withdrawal.

From TCPS (2005) Section 2E, 2.7:" "Many individuals who are not legally competent are still able to express their wishes in a meaningful way ... assenting to, or dissenting from, participation in research," including those "who once were capable of making an informed decision about informed consent, but whose competence is now considerably, but not completely, diminished, such as individuals with early Alzheimer's disease". University of British Columbia Clinical Research Ethics Board (CREB) interprets TCPS Article 2.7 as falling short of requiring the explicit assent of all such prospective subjects, and that failure to assent should not necessarily be construed as dissent. ${ }^{17}$ Therefore, assenting individuals may participate in research with the informed consent of an authorized third party; dissenting individuals may not. Those who neither clearly assent nor dissent require exercise of careful judgment on a case by case basis. Capacity to assent is present if the prospective subject has lost an adult capacity for appreciation but, nevertheless, has the capacity to understand the nature and consequences of the research (UBC CREB, Policy \#17). ${ }^{17}$

\section{The EXample of Immunotherapy Research Risks AND BENEFITS}

To date, there is limited information published on human trials of immunotherapy in Alzheimer's disease. The trials of 
immunization in mice and other animals demonstrated promising reduction in amyloid burden and seeming cognitive improvement. ${ }^{18,19}$ The Phase II immunotherapy trial for persons with AD, using AN-1792, enrolled 392 subjects with mild to moderate $\mathrm{AD}$ and the subjects received AN-1792 and placebo (4:1 ratio). Injections were given at baseline and 1, 3, 6, 9, and 12 months. Eighteen of 298 (6\%) developed subacute meningoencephalitis, 16 after 2 doses, 1 after 1 dose, and 1 after 3 doses, possibly due to T-cell and microglial activation. Twelve out of 18 recovered to baseline and $6 / 18$ continued to have disabling cognitive or neurological sequelae. ${ }^{20-22}$ Post-mortem study of at least one case of meningoencephalitis has been reported. ${ }^{23}$ Full data about clinical outcomes are not yet published. Hock et $\mathrm{al}^{20}$ using a tissue amyloid plaque immunoreactivity assay, determined that 20 of 30 of the subjects who generated antibody declined more slowly on tests of cognition and function than those without antibodies. They also noted that individuals in the study who received the antigen had improved cognition, function, and scores on the Wechsler Memory Scale, especially if antibodies were produced, with positive correlation of improvement to titre. The response was unrelated to acetyl choline esterase inhibitors (AChEI) treatments and distribution of apolipoprotein $\mathrm{E}$ (ApoE) genotype.

Because of the serious adverse events, the Phase II trial was stopped. With the cancellation of the trial, thoughtful literature has ensued. White and Hawke ${ }^{24}$ commented that further development of immunization against brain antigens must proceed with caution given the risk of T-cell meningitis and cerebral haemorrhage in animal studies associated with the generation of antibodies. Robinson et al reviewed the AN-1792 trials to date and said that there should be no further human studies until strategies have been more extensively tested on non-murine species. ${ }^{25}$ They noted their prediction of extensive Tlymphocyte infiltration of the brain. They also postulated that AN-1792 accelerates cognitive decline in AD patients who fail to acquire high antibody titres. McGeer and McGeer, noting that in AD complement is already overactivated, suggested that vaccination will increase production of the membrane attack complex adding to the autodestruction of neurons. ${ }^{26}$ They underlined that "what is beneficial in mice may be harmful in humans." Moreover, it has been suggested that some healthy elderly individuals as well as patients with AD harbour elevated baseline levels of $\mathrm{T}$ cells with a distinct Amyloid $\beta$ reactivity. ${ }^{27}$

So we are left with the moral foundation of equipoise: "the requirement that the health care of subjects not be disadvantaged by research participation" (TCPS, 2005, Section 1, 7.A). At the same time, opportunities to further understand the pathophysiology of a devastating disorder such as Alzheimer's disease and future treatments should not be lost. Further work is needed to continue human studies in immunotherapy in $\mathrm{AD}$, an intervention that appears to have more than minimal risk. Critical information can be gleaned from Phase II trial experience as the data is unblinded and potential benefit is disclosed. The literature, to date, has raised important questions that must be answered for ongoing human experimentation. Reflecting on the issue of maximal potential research risk including a new vaccine, Post noted that there is a lack of practical advice for monitoring harm and discomforts. ${ }^{28} \mathrm{He}$ noted that "researchers, family members, and other relevant observers must assume the primary and uncompromising role of subject advocate and protector".

In the example of immunotherapy studies with vaccines, extensive preclinical data across species should be available. Evaluation of the transport of amyloid and related antibodies, as well as the effects on the blood brain barrier, should be extensive to enable further human trials. The potential of a modified molecule for injection, which is less likely to provoke the T-cell response, is being explored. Mechanisms of action and their consequences must be better understood for the brain, the target of therapy and across organ systems that may also be affected.

It is likely that future therapies will have significant risks and there is a need for ongoing consideration of the ethical framework for making decisions to continue the important research, ultimately moving these therapies into clinical practise.

\section{Conclusion}

Research for subjects with AD must be pursued with appropriate safeguards in place. There are many areas of vulnerability for researchers and subjects alike, including understanding equipoise, risk, benefit, informed consent, proxy consent, and assent, all of which must be part of the consideration for a clinical trial in this population. There should be extensive data across species for new therapies especially where more than minimal risk is involved, as potentially riskier disease-modifying therapies are being proposed. Disclosure of all available information is required for researchers to allow subjects and their carers to make decisions weighing risk and benefit factors and finding genuine equipoise. Options for Double Informed Consent must be considered.

To further understand the complex issues in decision making for research studies in $\mathrm{AD}$ and related disorders, the following recommendations are made:

1. Undertake a study about Canadian caregivers' perceptions of benefits and burdens of their loved ones participating or not participating in $\mathrm{AD}$ research, both minimal risk and greater risk.

2. Undertake a survey of Canadian Research Ethics Boards approach to consent for potentially incompetent subjects and the incorporation of assent with an aim to standardize the approach to consent including assent.

3. Develop a framework for judging subject competence at the initiation of the trial and throughout the trial.

4. Develop specific strategies for meaningful feedback of trial results, including those with high risk.

\section{REFERENCES}

1. Tri-Council Policy Statement: Ethical Conduct for Research Involving Humans. Medical Research Council of Canada, Natural Sciences and Engineering Research Council of Canada, Social Sciences and Humanities Research Council of Canada. Public Works and Government Services Canada; 2005.

2. Emanuel EJ, Crouch RA, Arras JD, editors. Ethical and regulatory aspects of clinical research: readings and commentary. Baltimore, Maryland, USA. The Johns Hopkins University Press; 2003.

3. Buckles VD, Powlishta KK, Palmer JL, Coats M, Hosto T, Buckley $\mathrm{A}$, et al. Understanding of informed consent by demented individuals. Neurology. 2003; 61(12):1662-6.

4. Hirschman KB, Xie SX, Feudtner C, Karlawish JH. How does an Alzheimer's disease patient's role in medical decision making change over time? J Geriatr Psychiatry Neurol. 2004; 17(2): 55-60. 
5. Kim SY, Appelbaum PS, Jeste DV, Olin JT. Proxy and surrogate consent in geriatric neuropsychiatric research: update and recommendations. Am J Psychiatry. 2004; 161(5):797-806.

6. Pucci E, Belardinelli N, Borsetti G, Rodriguez D, Signorino M. Information and competency for consent to pharmacologic clinical trials in Alzheimer disease: an empirical analysis in patients and family caregivers. Alzheimer Dis Assoc Disord. 2001; 15(3):146-54.

7. Warren JW, Sobal J, Tenney JH, Hoopes JM, Damron D, Levenson $\mathrm{S}$, et al. Informed consent by proxy. An issue in research with elderly patients. N Engl J Med. 1986; 315(18):1124-8.

8. Ouslander JG, Tymchuk AJ, Rahbar B. Health care decisions among elderly long-term care residents and their potential proxies. Arch Intern Med. 1989; 149(6):1367-72.

9. Seckler AB, Meier DE, Mulvihill M, Paris BE. Substituted judgment: how accurate are proxy predictions? Ann Intern Med. 1991; 115(2):92-8.

10. Sachs GA. Advance consent for dementia research. Alzheimer Dis Assoc Disord. 1994; 8(Suppl. 4):S19-27.

11. Muncie HL, Jr., Magaziner J, Hebel JR, Warren JW. Proxies' decisions about clinical research participation for their charges. J Am Geriatr Soc. 1997; 45(8):929-33.

12. Williams BF, French JK, White HD. Informed consent during the clinical emergency of acute myocardial infarction (HERO-2 consent substudy): a prospective observational study. Lancet. 2003; 361(9361):918-22.

13. Lewis BS, Yuval R, Halon DA, Flugelman MY. Selection bias introduced by the informed consent process. Lancet. 2003; 361(9373):1990-1.

14. Sugarman J, Cain C, Wallace R, Welsh-Bohmer KA. How proxies make decisions about research for patients with Alzheimer's disease. J Am Geriatr Soc. 2001; 49(8):1110-9.

15. Karlawish JH, Casarett D. Addressing the ethical challenges of clinical trials that involve patients with dementia. J Geriatr Psychiatry Neurol. 2001; 14(4):222-8.

16. Beck C, Shue V. Surrogate decision-making and related issues. Alzheimer Dis Assoc Disord. 2003; 17 Suppl 1:S12-16.

17. Guidance notes for new applications for clinical ethical review by the UBC Clinical Research Ethics Board. Appendix 1. 2006. www.ors.ubc.ca/ethics/clinical/CREB_GN/CREB_Guidance_No tes.html.
18. Schenk D, Barbour R, Dunn W, Gordon G, Grajeda H, Guido T, et al. Immunization with amyloid-beta attenuates Alzheimerdisease-like pathology in the PDAPP mouse. Nature. 1999; 400(6740):173-7.

19. Schenk D. Amyloid-beta immunotherapy for Alzheimer's disease: the end of the beginning. Nat Rev Neurosci. 2002; 3(10):824-8.

20. Hock C, Konietzko U, Streffer JR, Tracy J, Signorell A, MullerTillmanns B, et al. Antibodies against beta-amyloid slow cognitive decline in Alzheimer's disease. Neuron. 2003; 38(4):547-54

21. Orgogozo JM, Gilman S, Dartigues JF, Laurent B, Puel M, Kirby LC, et al. Subacute meningoencephalitis in a subset of patients with AD after Abeta42 immunization. Neurology. 2003; 61(1):46-54.

22. Ferrer I, Boada RM, Sanchez Guerra ML, Rey MJ, Costa-Jussa F. Neuropathology and pathogenesis of encephalitis following amyloid-beta immunization in Alzheimer's disease. Brain Pathol. 2004; 14(1):11-20.

23. Nicoll JA, Wilkinson D, Holmes C, Steart P, Markhan H, Weller RO. Neuropathology of human Alzheimer disease after immunization with amyloid-beta peptide: a case report. Nat Med. 2003; 9(4):448-52.

24. White AR, Hawke SH. Immunotherapy as a therapeutic treatment for neurodegenerative disorders. J Neurochem. 2003; 87(4): 801-8.

25. Robinson SR, Bishop GM, Lee HG, Munch G. Lessons from the AN 1792 Alzheimer vaccine: lest we forget. Neurobiol Aging. 2004; 25(5):609-15.

26. McGeer PL, McGeer E. Is there a future for vaccination as a treatment for Alzheimer's disease? Neurobiol Aging. 2003; 24(3):391-5

27. Heppner FL, Gandy S, McLaurin J. Current concepts and future prospects for Alzheimer disease vaccines. Alzheimer Dis Assoc Disord. 2004; 18(1):38-43.

28. Post SG. Full-spectrum proxy consent for research participation when persons with Alzheimer disease lose decisional capacities: research ethics and the common good. Alzheimer Dis Assoc Disord. 2003; 17 Suppl 1:S3-11. 